\title{
Feedback on Grammatical Accuracy: Comparing Perceptions and Practices on the Teachers' and Learners' Parts
}

Fahimeh Ashja Nazarloo, Massoud Yaghoubi-Notash*

Department of English Language \& Literature, Faculty of Persian Literature \& Foreign Languages, Tabriz University Tabriz, Iran

Corresponding author: Massoud Yaghoubi-Notash, E-mail: masoud.yaghoubi@gmail.com

\section{ARTICLE INFO}

Article history

Received: June 28, 2018

Accepted: October 07, 2018

Published: October 31, 2018

Volume: 6 Issue: 4

Conflicts of interest: None

Funding: None

\begin{abstract}
An advantage of the communication-based instruction in an EFL situation is prioritizing fluency and meaning negotiation though of course at the cost of accuracy. Researchers have, therefore, found feedback on the learners' erroneous utterances quite appealing so that form can be attended to against the wider backdrop of meaning-focused involvement in communication. This present study qualitatively and quantitatively sought to investigate the teachers' and intermediate learners' perceptions as well as the teachers' practices concerning corrective feedback types, sources of feedback, and types of grammatical errors that occur and need to be attended to during the classroom conversations. The study was conducted in two private language institutes in Tabriz, Eastern Azerbaijan Province, Iran. The instructional materials were Top Notch course books. For the purpose of the study, 6 teachers and 60 EFL learners were focused on. First, the classes of 6 teachers were observed. Then, the teachers and learners completed a questionnaire on corrective feedback. The results indicated that learners showed strong agreement toward using explicit feedback. On the contrary, teachers usually neglected the learners' grammatical errors at the classroom to maintain the flow of interaction. Another important finding about sources of feedback was that teachers and learners preferred teacher correction to peer correction or selfcorrection. Finally, both teachers and learners expressed strong agreement about feedback on serious grammatical errors during conversation though the former tended to agree more with the feedback on less serious and frequent grammatically erroneous utterances.
\end{abstract}

Key words: Correction Feedback, Explicit, Grammatical Accuracy, Practice, Perception

\section{INTRODUCTION}

Dealing with the erroneous structures and forms emerging in the learners' language during language instruction can be of high interest to ESL/EFL practitioners. This calls for a special attention to feedback as a pivotal instructional concern. According to Ellis (2006), corrective feedback is a kind of reaction to the learners' erroneous utterances. Sheen (2011) defines CF as "a teacher's reactive move that invites learners to attend to the grammatical accuracy of something they have said or written" (p. 1). Excessive grammar in isolation is challenging and the learners exposed to this type of instruction fail to perform well in communicative contexts. In other words, the instruction that focuses exclusively on forms distracts the learners' attention from the communication such that fluency as a central part of communication is sacrificed. According to Ellis, Basturkmen, and Loewen (2002), "[a] quintessential example of a focus-on-forms lesson is one conducted by means of PPP (i.e. a three stage lesson typical in Situational Language Teaching encompassing the presentation of a grammatical structure, its practice in controlled drills and the provision of opportunities to produce it freely)" (cited in Khatib \& Derakhshan, 2011, p.866). The other type of instruction that sounds more plausible is focus-on-form which improves both the learners' fluency and accuracy. According to Ellis (2003), the concentration on form in wider context of communication is called methodological focus on form. In another study, Ellis et al. (2002) state that two types of form-focused instructions can be distinguished, namely planned focus-on-form and incidental focus-on-form. Corrective feedback can be a kind of methodological focus on form that can improve the learners' accuracy by both positive and negative evidence. Therefore, different corrective strategies cane used for correcting the learners' grammatical errors. Feedback can be used both explicitly (such as giving overt error correction) and implicitly (e.g., by repetition, recast, or using facial expressions). The most important taxonomy of corrective feedback has been presented by Lyster and Ranta (1997) that classified corrective feedback into six categories including: explicit correction, recast, metalinguistic feedback, elicitation, repetition, and clarification request.

\section{LITERATURE REVIEW}

Form-focused instruction (FFI) and meaning-focused instruction are components of instructed second language ac- 
quisition. Form-focused instruction can be divided in two parts as FOF and FOFs. According to Housen and Pierrard (2005), instructed second language acquisition can indicate "any systematic attempt to enable or facilitate language learning by manipulating the mechanisms of learning and/ or the conditions under which these occur" (p.3). In other words, instructed second language acquisition occurs in classroom context and it is different from acquiring language in real context. We can view formal instruction as a context which raises the learner's awareness of target language structure.

Lyster (2007) believes that FFI options are generally considered most effective when implemented in communicative contexts, to ensure that learners will be able to transfer what they learn in the classroom to communicative interaction outside the classroom. According to Ellis, Basturkmen and Lowen (2001), FFI refers to any planned or incidental instructional activity that is intended to which consists of attention to language items during communicative activities but the difference is that these language items have been selected before the activity. The main difference between FoF (Focus on Form) and FoFs (Focus on Forms) is the degree to which teachers focus on grammatical errors. Some teachers insist on correcting the learner's grammatical errors separately and they don't want to correct the errors in communicative context. But some teachers are sensitive to interruption. They focus on grammatical errors very briefly within communicative context. The former is identified as FoFs, whereas the latter focused on FoF.

\section{Corrective Feedback}

Errors generally tend to be seen as unpleasant occurrences that have be avoided or prevented. An important aspect of second language acquisition which attracted learners and teachers' attention is corrective feedback $(\mathrm{CF})$ that has stimulated a wealth of studies. CF is a type of feedback which the learners receive for their errors. Ellis (2006, p. 28) defines $\mathrm{CF}$ as "responses to learner utterances containing an error". Sheen and Ellis (2011) believe that CF works when learners notice the errors they have committed. They state that $\mathrm{CF}$ gives the learners an opportunity to "notice the gap" (p. 23) and compare their production with the CF which they have received. Some researchers dismiss the role of CF in L2 acquisition but others view $\mathrm{CF}$ as necessary part of language learning. Krashen (1982, p.74) believed that error correction is "a serious mistake". As cited in Ellis (2009), he offered two main reasons for this view. Krashen (1982) believes that "error correction has the immediate effect of putting the student on the defensive" (p. 75). Second, error correction is affective in the development of "learned knowledge" (1982, p. 75) and plays no role in "acquired knowledge" (1982, p. 75). On the other hand, some researchers believe that $\mathrm{CF}$ raises the learners' awareness through which they notice the differences between target language structure and output.

There are two other key terms which are positive evidence and negative evidence. According to Long (1996), two input types are identified in SLA, namely positive evidence and negative evidence. She believes that the former refers to information about the utterances which are acceptable in the target language. The latter, on the other hand, is information about the utterances or types of utterances that are impossible in the language.

These corrective strategies can be classified into the dichotomous category of implicit and explicit. Lyster and Ranta (1997) believe that corrective feedback occurs as the learners move into an interaction. Lyster and Ranta (1997) classify all corrective feedback moves into either of the two types: reformulations or prompts. Reformulation is correcting all or part of a learner's erroneous utterance while prompts encourage learners to correct their errors themselves. Ellis (2009) suggests that one of the standard procedures in error analysis is reconstruction, "That is, in order to identify an error, the analyst (and the teacher) needs to construct a native speaker version of that part of the text containing an error" (p. 103). He believes that reformulation as a technique grew out of this procedure. Recast and explicit correction belong to reformulation category because a competent speaker or teacher corrects the erroneous utterance. However, Lyster and Ranta (2007) believe that prompts include different signals to push the learners to self-repair. These include elicitation, metalinguistic clues, clarification requests, and teacher repetition. Ellis and Sheen (2011) define reformulation as input-providing feedback (i.e. the teacher or peer provide the correct form) and prompts as output prompting feedback (i.e., eliciting correct answer from the learner). Furthermore, CF can be both immediate and delayed. Sheen and Ellis (2011) acknowledged that oral CF can involve both on-line attempts and off-line attempts. In on-line attempts, the feedback is provided to the learner immediately after erroneous utterance has finished. But off-line attempts try to provide $\mathrm{CF}$ and correct the learners' erroneous utterance after communication event has finished.

Although main goals of research were to investigate the teachers' practices and learners' perceptions of different types of corrective feedback, sources of feedback, and types of errors to be corrected, a range of studies have examined the teachers' perceptions and learners' perceptions about corrective feedback. The focus of this sub-section is on these types of studies.

Various studies have addressed feedback and different results have been obtained. For example, according to Ellis (1994), recast provides the opportunity to notice form while the focus on the meaning is maintained. Mackey, Gass, and McDonough (2000 as cited in Braidi, 2002, p.12) examined recast as one type of negative feedback. The result indicated that recast as an interactional feedback may not be perceived by the learners as negative feedback and their effect on the development of learners should be addressed.

In another study, Lyster and Mori (2006) investigated the distribution of different types of interactional feedback in French and Japanese immersion classrooms. The result suggested that recasts constituted the most important feedback in both situations. In other words, teachers in both contexts had similar behavior in their feedback choices. Also, they used recast more than other types of feedback.

According to Loewen and Nabei (2007), clarification request provides the opportunity for the learners to attend to 
the forms. On the other hand, Carrol (2001, as cited in Rassaei and Moinzadeh, 2011, p. 98) reported that the learners receiving explicit corrective feedback outperformed those who received implicit error correction. Similarly, following Ellis, Loewen, and Erlam (2006, as cited in Rassaei \& Moinzadeh, 2011, p. 98) the learners who received metalinguistic feedback did better than those who received recasts in a delayed post-test, while no difference was observed between the groups in the immediate post-test.

Amador (2008) also examined learners' ideas about the CF types and their ideas about the correctors suggesting that the learners favored the explicit CF strategies. Another study done in Finnish context by Kivelä (2008) focused on the pupils' oral errors and teachers' practices on error correction. The results showed that phonological errors $(52 \%)$, grammatical errors (23\%) and lexical errors (22\%) were the most common. Of all of these errors, lexical and grammatical errors were corrected very often ( $93 \%$ and $81 \%$, respectively). The other important finding was that most of the errors was corrected by teachers $(66 \%)$ and sometimes was corrected by peers $(15 \%$ of the data) and by the student $(15 \%)$. The last finding of this research is about the CF strategy where the most typical error correction strategies involved recasts and negotiations.

Park (2010) could show that all of the groups preferred recast to all other five strategies of CF proposed by Lyster and Ranta (1997). Also, explicit correction was the only CF approach distinguishing teachers and learners, and the high and low proficiency students. Participants' views about the CF did not vary significantly. In qualitative terms, Park (2010) could show that the groups demonstrated a big difference regarding $\mathrm{CF}$ strategies both by the teachers and learners. Similarly, Al-Faki and Siddiek (2013) compared teachers' perception and practice with learners' perception of oral CF. Recast, elicitation, and questioning (peer-correction) were the most frequently used types of oral corrective feedback and recast had the highest usage in teachers 'practice. There were main differences, nevertheless, between the teachers' practices in the two cycles of the Basic Educational System. Teachers in C2 mostly used repetition, metalinguistic feedback, clarification request, questioning (self-correction) and explicit correction but they had a very low usage of these in PB. In addition, students expected specific oral corrective feedback types from their teachers.

A classroom observation by Sung and Tsai (2014) revealed that the most frequently used CF type was recast at the beginner (48\%) as well as the advanced (41.2\%) levels, but that a majority of the beginners favored recast as a suitable corrective feedback strategy. This, however, did not apply in the case of advanced learners who preferred recasts for correcting pronunciation and grammar errors, explicit correction and meta-linguistic feedback for correcting misunderstanding of the teachers' speech, and explicit correction for correcting lexical errors.

Calsiyao (2015) investigated the corrective feedback on classroom oral errors through interview and reported that the learners preferred all errors to be corrected, but usually expected corrections for grammar and pronunciation.
Additionally, learners preferred recast and explicit correction, and explanation for grammatical errors but explicit feedback and explanation for mispronunciation. With this background in mind.

\section{RESEARCH QUESTIONS}

1. Is there any significant difference between the teachers' perceptions and learners' perceptions in terms of feedback source (corrector)?

2. Is there any significant difference between the teachers' perceptions and learners' perceptions in terms of error types?

3. Is there any significant difference between the teachers' practices and learners' perceptions in the type of CF?

\section{METHODOLOGY}

\section{Study Setting and Participants}

Participants of the study were 60 intermediate-level students (25 males and 35 females) and 6 female teachers from two private language institutes in Tabriz, Eastern Azerbaijan Province, Iran. The number of the learners in each class ranged from 1 to 14 and one class from each of the teachers were selected. The learners' age ranged from 15 to 25 . Each semester comprised 16 class sessions each taking 90 minutes that met three times a week. All of the learners were from Tabriz and their mother language was Azerbaijani.

\section{Design and Procedures of the Study}

The present study is a mixed method design composed of both qualitative and quantitative analyses. Two methods of data collection were used in this study, namely observation and questionnaire for learners. These two methods led to two stages in data collection. The first stage was observation of six teachers' classes. Before observing the class, the researchers informed the teachers of the general objectives but she delayed explaining the specific objective of the study until the end of the observation. By contrast, the learners weren't given any information on the purpose of observation. To this end, they tried to choose a topic for learners to prepare prior to the class, since teachers wanted their learners to think about the topic to have the right background in mind. First, the researchers and two other evaluators observed each teacher's classes regarding a) provision of teachers' feedback while the learners we reproducing grammatical errors in the communication and b) how the teachers were dealing with the learners' grammatical errors during communication. Then the interactions were audio-recorded by three evaluators. An average of 16 hours of classroom interactions was recorded. And, after recording, all the applied corrective feedback instances were transcribed. The purpose of this stage was to understand the teachers' practices in grammatical error correction.

The next stage of data collection was questionnaire for both teachers and learners to understand the attitude toward corrective feedback. The questionnaires contained 5-point 
scales in the Likert format (e.g., Highly Effective, Somewhat Effective, I don't know, Somewhat ineffective, Highly Ineffective). In order to ensure the clarity of the questionnaire data, piloting was conducted. The piloting was done with 15 learners, and high reliability for different parts of the questionnaire was obtained $($ Cronbach Alpha $=0.85)$.

The questionnaire contained three sections. The first part addressed different types of CF. Teachers' practice may be different from learners' idea in the type of feedback they choose. Thus, it was necessary to elicit responses both from the learners and teachers. The second section pertained to the person who corrected the errors or the source of correction. The learners' attitude may be different from the teachers' attitude toward the person who corrected the errors. Thus, this part of the questionnaire helped teachers to understand about learners' ideas. The last part of the questionnaire was about the type of errors that should be corrected. There are different kinds of errors that were mentioned in the questionnaire. Responding to this section, teachers can match their practice with the learners' beliefs regarding successful teaching. The teachers and learners were asked to mark the best answer to show their beliefs. The data that were obtained from the questionnaire were numerical.

The final stage involved two sets of data to compare the teachers' practice with the learners' and teachers' perception. In other words, the aim of this research was to make a better understanding of the differences and similarities among the teachers' perceptions and practices and learners' perceptions.

\section{DATA ANALYSIS AND RESULTS}

\subsection{Descriptive Statistics}

All the data were computed by Statistical Package for the Social Science (SPSS, Version 22). Descriptive statistics were obtained to have the mean and standard deviation values and for a general understanding of the nature of the data. However, inferential statistics is required for a closer understanding of the causal relations. In other words, inferential statistics should be used to come to conclusive results. For the present study, Wilcoxon Test was employed.

\subsection{Testing the First Hypothesis}

Table 1 summarizes the descriptive statistics for the source of feedback. In other words, it provides general information on the teachers' and learners' perception toward the person who corrects the errors. Pair 1 asks learners' and teachers' ideas about the corrector that is teacher. As shown in Table 1, the learners' mean score $(M=4.93, S D=0.251)$ and teachers' mean score $(M=4.83, S D=0.375)$ are close and the amount of these mean scores are high. Thus, pair one denotes that both teachers and learners show a high tendency to teacher correction. But, accurate results will be explained in Table 2 (Wilcoxon Test). On the contrary, pair two, which was about the teachers' and learners' tendency to peer correction, received lower mean score. Mean score of learners' perceptions is $2.35(M=2.35, S D=1.23)$ and mean score of teachers' perception is $2.83(M=2.83, S D=1.07)$. Pair 3 is
Table 1. Descriptive statistics for the teachers' and learners' perception about the source of feedback (correctors)

\begin{tabular}{ccccc}
\hline \multicolumn{5}{c}{ Paired samples statistics } \\
\hline & Mean & $\mathbf{N}$ & $\begin{array}{c}\text { Standard } \\
\text { deviation }\end{array}$ & $\begin{array}{c}\text { Standard error of } \\
\text { measurement }\end{array}$ \\
\hline Pair 1 & & & & \\
T/LP & 4.93 & 60 & 0.25 & 0.032 \\
T/TP & 4.83 & 60 & 0.37 & 0.048 \\
Pair 2 & & & & \\
C/LP & 2.35 & 60 & 1.23 & 0.159 \\
C/TP & 2.83 & 60 & 1.076 & 0.13 \\
Pair 3 & & & & \\
S/LP & 3.10 & 60 & 1.63 & 0.21 \\
S/TP & 3.16 & 60 & 1.22 & 0.15 \\
Total & & & & 0.09 \\
T/LP & 3.46 & 60 & 0.75 & 0.08 \\
T/TP & 3.6 & 60 & 0.65 & \\
\hline
\end{tabular}

T/LP: Teacher learner perception; T/TP: Teacher/teacher Practice; C/LP: Classmate/learner Perception, Student/learner Perception, Teacher (corrector)/Learner perception, Teacher (corrector)/Teacher perception

Table 2. Wilcoxon test between the teachers' and learners' perceptions about the correctors

\begin{tabular}{lcccc}
\hline \multicolumn{1}{l}{ Test statistics } & & & & \\
\hline & TP & TP & TP & TP \\
& LP & LP & LP & LP \\
& TC & PC & SC & Total \\
$Z$ & -1.604 & -2.185 & -0.287 & -1.119 \\
$p$ & 0.109 & 0.029 & 0.774 & 0.263 \\
\hline
\end{tabular}

TP: Teacher's perception, LP: Learner's perception, TC: Teacher correction, PC: Peer correction, SC: Self correction

about the learners' and teachers' preferences about the corrector who is learner himself or herself. The obtained mean score for learners' perception is $3.10(M=3.10, S D=0.210)$ and mean score of teachers' preference is $3.16(M=3.16$, $S D=0.15)$. We can conclude that some learners and teachers showed willingness to have their errors corrected by the learner himself or herself.

Nevertheless, Wilcoxon Test can give an accurate picture of the differences and similarities between the teachers and learners. The researchers wanted to ensure that there was no significant difference among two groups of the study.

Having analyzed the data, the researchers could demonstrate that two groups had the same idea about the source of feedback, and there was no significant difference between the teachers' perceptions and that of the learners. The Wilcoxon test results appear in Table 2

Wilcoxon Test was used to obtain the $p$ value for three sources of feedback (correctors). As illustrated in this table, the obtained $p$ value for the teacher as a corrector is 0.109 which is larger than the critical $p$ value $(p=0.109, p \geq 0.05)$. 
This suggests that alternative hypothesis can be rejected and null hypothesis should be accepted. As noted in Table 2, the obtained values representing perception of teachers' and learners' mean values are 4.83 and 4.93, respectively. In other words, both teachers and learners showed strong agreement towards using teacher as the corrector.

The next source of feedback involved peer correction. The obtained $p$ value for peer correction is 0.029 . As indicated, $p$ value is lower than the significance level $(p=.109, p>0.05)$. Therefore, null hypothesis should be rejected and alternative hypothesis can be accepted. In other words, teachers and learners have significantly different ideas about peer correction.

The last corrector was the learner himself or herself. As indicated in the table above, the obtained $p$ value for this corrector is 0.774 . In other words, $p$ value is higher than 0.05 . Therefore, null hypothesis can be accepted. In other words, teachers and learners have similar ideas about this corrector. Similarly, the total $p$ value that is 0.263 indicated that null hypothesis can be accepted in other words, teachers and learners have similar ideas about the corrector.

\subsection{Testing the Second Hypothesis}

Preferences toward serious errors and frequent errors appear in Table 3 that is pair 1 and pair 3, respectively. Accordingly, students' perceptions with the following mean scores are so close to teachers' perceptions in both serious errors and frequent errors. However, as mentioned before a careful examination of details in Table 4 that indicates inferential statistics about this research question. As shown in the table, the serious errors' and frequent errors' $p$ values are higher than the significance level $(p=0.055$ and 0.44 , respectively, $p \geq 0.05$ ). As illustrated, higher $p$ value indicated that teachers and learners have similar ideas about the serious and frequent grammatical errors that should be corrected in the conversation. Accordingly, null hypothesis can be rejected and we can accept alternative hypothesis. Additionally, a careful look at mean scores illustrates the fact that both teachers and learners showed strong agreement with correcting serious and frequent errors. Their differences are less than one unit. With other pairs, the second and fourth pairs, the students and teachers were asked about their preferences towards less serious errors that do not affect listeners' understanding and individual errors. As it is indicated in Table 3, pair 2 and 4, two mean scores and standard deviations differ in value. The obtained mean score in pair 2 for learners' perceptions is $3.01(M=3.01, S D=0.92)$ and teachers' perceptions mean score is $3.83(M=3.83, S D=0.37)$. With pair four, the obtained mean score for learners' perceptions is $4.11(M=4.08, S D=0.13)$. But, the obtained mean score for the teachers' perceptions is $4.00(M=4.50, S D=0.06)$.

However, as illustrated, rejection or accepting of the hypothesis cannot be explained by mean scores and standard deviations. Therefore, the Wilcoxon Test was used to find out whether there were significant differences between the teachers' and learners' perceptions in choosing less serious errors and individual errors that should be corrected. As indicated, $p$ value $\mathrm{s}$ for these two types of errors are 0.00
Table 3. Descriptive statistics for the teachers' and learners' perception about the type of errors

\begin{tabular}{|c|c|c|c|c|}
\hline \multicolumn{5}{|c|}{ Paired samples statistics } \\
\hline & Mean & $\mathbf{N}$ & SD & SEM \\
\hline \multicolumn{5}{|l|}{ Pair 1} \\
\hline $\mathrm{SE} / \mathrm{LP}$ & 4.65 & 60 & 0.54 & 0.070 \\
\hline $\mathrm{SE} / \mathrm{TP}$ & 4.83 & 60 & 0.37 & 0.048 \\
\hline \multicolumn{5}{|l|}{ Pair 2} \\
\hline LFE/LP & 3.01 & 60 & 0.92 & 0.120 \\
\hline $\mathrm{LFE} / \mathrm{TP}$ & 3.83 & 60 & 0.37 & 0.048 \\
\hline \multicolumn{5}{|l|}{ Pair 3} \\
\hline $\mathrm{FE} / \mathrm{LP}$ & 4.11 & 60 & 0.97 & 0.125 \\
\hline $\mathrm{FE} / \mathrm{TP}$ & 4.00 & 60 & 0.58 & 0.075 \\
\hline \multicolumn{5}{|l|}{ Pair 4} \\
\hline IE/LP & 4.08 & 60 & 1.06 & 0.13 \\
\hline $\mathrm{IE} / \mathrm{TP}$ & 4.50 & 60 & 0.50 & 0.065 \\
\hline \multicolumn{5}{|l|}{ Total } \\
\hline Total /LP & 3.96 & 60 & 0.53 & 0.069 \\
\hline Total /TP & 4.29 & 60 & 0.17 & 0.022 \\
\hline
\end{tabular}

SE: Serious errors, LP: Learner perception, TP: Teacher perception, LFE: Less frequent errors, FE: Frequent errors, IE: Individual errors

Table 4. Wilcoxon test between the teachers' and learners' perceptions about the error types

\begin{tabular}{cccccc}
\hline \multicolumn{1}{c}{ Test statistics } & & & & \\
\hline & TP & TP & TP & TP & TP \\
& LP & LP & LP & LP & LP \\
& SE & LSE & FE & IE & Total \\
Z & -1.919 & -4.783 & -.771 & -2.399 & $-3.684^{b}$ \\
$p$ & 0.055 & 0.00 & 0.44 & 0.016 & 0.00 \\
\hline
\end{tabular}

TP: Teacher perception, LP: Learner perception, SE: Serious Errors, LSE: Less serious errors, FE: Frequent errors, IE: Individual errors.

and0.016, respectively ( $p=.000$ and.016, $p \leq 0.05$ ). As can be understood from these numerical values, there are some differences between the teachers' and learners' ideas in choosing the error that should be corrected. In other words, a careful look at mean scores indicates that learners showed strong agreement towards correcting both less serious errors and individual errors in comparison to teachers.

The total $p$ value that have been obtained is 0.000 $(p<0.05)$. As shown, total $p$ value is smaller than critical value. Therefore, null hypothesis can be rejected and it can be claimed that teachers and learners have different ideas about the type of grammatical errors that should be corrected.

\subsection{Testing the Third Hypothesis}

Research question 3 discusses the teachers' practices and learners' perceptions in relation to the type of corrective feedback. Both descriptive statistics and inferential statistics were used for answering this research question. Six types 
of corrective feedback were included in this part namely no correction, repetition, explicit correction, elicitation, metalinguistic feedback, and recast. Descriptive data for the teachers' practice and learners' perception about the type of CF are given in Table 5. As Table 5 illustrates, the mean score of teachers' practice in pair one which is about 'no correction' is $4.83(M=4.83, S D=0.37)$, and the mean score about the learners' perception is $1.31(M=1.31, S D=0.56)$. And, variance between two standard deviations is considerable. In other words, mean score of teachers' practice is higher than the mean score of learners' perception. In spite of the fact that teachers usually ignored earners' errors at the class, but learners disagreed with the idea of ignoring grammatical errors.

The next pairs stand for the result of students' preferences and teachers' practices about repetition, explicit correction, elicitation, and metalinguistic feedback. As explained in Table 5, mean scores of learners' perceptions and teachers' practices differ by one single unit. Similarly, their standard deviations are at variance. In other words, different men scores show the difference between teachers' practices and learners' perception. In other words, the results of observation indicated that teachers hardly ever used repetition, explicit correction, elicitation, and metalinguistic feedback for grammatical error correction and they ignored them by continuing the conversation.

The last type of feedback which is about recast has been indicated in Table 5. As can be seen from the table, two mean scores are very close. In other words, mean score of learners' perceptions and teachers' practices are 1.61 and 1.66, respectively. Mean scores and standard deviations indicate that teachers' practice is the same with the learners' idea about this feedback. Interestingly, teachers seldom used recast at the classroom and learners did not like to be corrected by this kind of feedback.

Descriptive analyses were conducted to juxtapose the differences and similarities between the teachers' practices and learners' perceptions. As noted, descriptive statistics cannot be the basis for rejection or acceptance of the hypothesis. Therefore, Wilcoxon Test was conducted to examine the differences and similarities between the teachers' practices and learners' perceptions about the type of CF.

The first type represents 'no correction' that the teachers do not correct the learners. Table 6 indicates the $p$ value that is lower than significant level ( $p=0.000, p \leq 0.05$ ). The obtained $p$ value indicates the differences between the teachers' practices and learners' perceptions. Therefore, null hypothesis is rejected and alternative hypothesis can be accepted. With a glance at the mean scores, it can be concluded that teachers did not correct learners, whereas, most of the learners had positive view towards error correction.

Wilcoxon Test was used to elicit the exact results about repetition, explicit correction, elicitation, and metalinguistic feedback, respectively. As shown in Table 5, the obtained $p$ values are less than the significant level for all CF types. As explained before, their mean scores are not close to each other. Inferential statistics can indicate statistically significant difference between the learners' and teachers' practices.
Table 5. Descriptive statistics for the teachers' practices and learners' perceptions about the type of CF

\begin{tabular}{|c|c|c|c|c|}
\hline \multicolumn{5}{|c|}{ Paired samples statistics } \\
\hline & Mean & $\mathbf{N}$ & SD & SEM \\
\hline \multicolumn{5}{|l|}{ Pair 1} \\
\hline NC/LP & 1.31 & 60 & 0.56 & 0.073 \\
\hline NC/TP & 4.83 & 60 & 0.37 & 0.048 \\
\hline \multicolumn{5}{|l|}{ Pair 2} \\
\hline $\mathrm{RE} / \mathrm{LP}$ & 3.55 & 60 & 1.26 & 0.16 \\
\hline $\mathrm{RE} / \mathrm{TP}$ & 3.00 & 60 & 0.00 & 0.00 \\
\hline \multicolumn{5}{|l|}{ Pair 3} \\
\hline EC/LP & 4.28 & 60 & 1.04 & 0.13 \\
\hline $\mathrm{EC} / \mathrm{TP}$ & 1.83 & 60 & 0.37 & 0.048 \\
\hline \multicolumn{5}{|l|}{ Pair 4} \\
\hline $\mathrm{EL} / \mathrm{LP}$ & 4.18 & 60 & 0.77 & 0.01 \\
\hline $\mathrm{EL} / \mathrm{TP}$ & 2.00 & 60 & 0.58 & 0.075 \\
\hline \multicolumn{5}{|l|}{ Pair 5} \\
\hline $\mathrm{MF} / \mathrm{LP}$ & 2.16 & 60 & 1.22 & 0.15 \\
\hline $\mathrm{MF} / \mathrm{TP}$ & 1.16 & 60 & 0.37 & 0.048 \\
\hline \multicolumn{5}{|l|}{ Pair 6} \\
\hline $\mathrm{R} / \mathrm{LP}$ & 1.61 & 60 & 0.82 & 0.10 \\
\hline $\mathrm{R} / \mathrm{TP}$ & 1.66 & 60 & 0.47 & 0.06 \\
\hline \multicolumn{5}{|l|}{ Total } \\
\hline $\mathrm{T} / \mathrm{LP}$ & 2.85 & 60 & 0.45 & 0.06 \\
\hline $\mathrm{T} / \mathrm{TP}$ & 2.41 & 60 & 0.12 & 0.016 \\
\hline
\end{tabular}

NC: No-correction, LP: Learner perception, TP: Teacher perception, RE: Repetition, EC: Explicit correction, EL: Elicitation, MF: Metalinguistic Feedback, R: Recast

Table 6. Wilcoxon Test between the teachers' practices and learners' perceptions about CF types

\begin{tabular}{|c|c|c|c|c|}
\hline \multicolumn{5}{|c|}{ Test statistics } \\
\hline & $\mathrm{NC} / \mathrm{TP}$ & RE/TP & $\mathrm{EC} / \mathrm{TP}$ & $\mathrm{EL} / \mathrm{TP}$ \\
\hline & $\mathrm{NC} / \mathrm{LP}$ & RE/LP & $\mathrm{EC} / \mathrm{LP}$ & EL/LP \\
\hline Z & -6.954 & -3.014 & -6.717 & -6.687 \\
\hline \multirow[t]{5}{*}{$p$} & 0.000 & 0.003 & 0.000 & 0.000 \\
\hline & $\mathrm{MF} / \mathrm{TP}$ & $\mathrm{R} / \mathrm{TP}$ & $\mathrm{T} / \mathrm{TP}$ & \\
\hline & $\mathrm{MF} / \mathrm{LP}$ & $\mathrm{R} / \mathrm{LP}$ & $\mathrm{T} / \mathrm{LP}$ & \\
\hline & -5.033 & -0.664 & -5.096 & \\
\hline & 0.000 & 0.507 & 0.000 & \\
\hline
\end{tabular}

NC: No-Correction,LP: Learner perception, TP: Teacher perception, RE: Repetition, EC: Explicit correction MF: Metalinguistic Feedback, R: Recast

Therefore, the null hypothesis should be rejected. Comparing mean score, we can claim that learners showed strong agreement with all these four feedback types. In contrast, teachers used them less at the class.

The last feedback type that was shown in the above table is recast. As is seen in Table 5, the obtained mean scores for teachers and learners are 1.66 and 1.61, respectively. As 
noted, we cannot judge by descriptive statistics that whether there are differences between practice and perception or not. The obtained $p$ value $(p=0.507, p \geq 0.05)$ from Wilcoxon Test failed to support a significant difference between the learners' ideas and the teachers' practices in using recast at the class. In other words, not only learners disagreed with correction with recast, but also, the teachers did not correct the learners with this strategy. Therefore, we can accept the null hypothesis.

As it is clear in Table 6, the Wilcoxon test revealed that there were significant differences between teachers' practice and learners' perception about first five CF types and it was only recast in which the significant differences between teachers' practices and learners' perceptions did not appear. Therefore, the obtained total $p$ value $(p=.000, p \leq 0.05)$ which suggests that there is a significant difference between the learners' perceptions and teachers' practices.

\section{DISCUSSION}

As mentioned earlier, the main concern of this study was to investigate the differences and similarities among the learners' perceptions and teachers' perceptions and practices in choosing different kinds of feedbacks, type of errors to be corrected, and the source of feedback or correctors. Although there might not be a one-to-one correspondence between teachers' and learners' perceptions or teachers' practices and learners' perceptions, this issue involves quite a lot of potentials for research.

According to Burns (1992), “the teachers' verbalizations reflect something of the interplay between belief and decision-making constantly operating beneath the surface of more observable classroom language and behavior" (p.63). Exploring the link between the teachers' perceptions and the learner' perceptions revealed that they have the same idea about the source of feedback or correctors. In other words, the first corrector is the teacher and both teachers and learners were asked about such a source of correction. Both teachers and learners showed strong agreement towards teacher-correction in grammatical errors during conversation. In other words, learners would like to be corrected by their teacher and teachers would like themselves to correct the learners' grammatical errors during conversation. Therefore, there are no significant differences between teachers' perceptions and learners' perceptions in choosing the teacher as a corrector.

The other corrector is peer. The findings suggested that both learners and teachers disagreed with peer-correction. The important point to consider is that teachers showed strong disagreement towards peer correction in comparison with the learners' ideas. More specifically, there are significant differences between teachers' perceptions and learners' perceptions in choosing peers as the source of correcting the learners' grammatical errors during conversation.

The other corrector that was investigated in this research was the learner himself or herself. The findings showed that both teachers and learners did not disagree with learners' self-correction. However, it was evident that both teachers and learners' agreement was not as strong as teacher-correction.

Altogether, both teachers and learners showed strong agreement toward teacher-correction more than peer-correction or correction by the learner himself or herself. But the last finding illustrated that teachers showed strong disagreement toward peer correction in comparison to the learners.

The findings of the present study are in line with those of many researchers (Asmara, 2015; Kivelä, 2008; Renko, 2012; Suwangard, 2014) who delineated that learners believed in teacher correction more than peer correction. The reason for this choice can be that the majority of the learners believed that correcting grammatical errors by the teachers was more reliable in comparison to peer correction or self-correction.

The findings of this study are somehow supported by Liao and Wang (2009) where learners believed in teacher-correction. On the other hand, the difference is that Liao and Wang (2009) found that the majority of teachers demonstrated strong preferences towards learners' self-correction. In other words, the teachers believed that grammatical error correction leads to anxiety in learners. On the contrary, the learners in this research believed in teacher-correction rather than peer-correction or self-correction.

The second research question of the current study concerned the differences or similarities between teachers' and learners' perceptions in correcting different error types. In other words, this research question investigated different types of errors about which teachers and learners were consulted. The first and third type of errors which referred to serious errors and frequent errors illustrated the teachers' and learners' strong agreement toward the correction of these errors. In other words, the researchers concluded that the serious errors and frequent errors made by the students should be corrected by the teachers.

The next two error types (i.e. less serious errors and individual errors) accounted for another differences between teachers' and learners' ideas. Unlike the learners, teachers did want the learners' serious grammatical errors and individual grammatical errors to be corrected during the conversation. On the contrary, learners disagreed with the correction of these error types. Altogether, teachers' perceptions and learners' perceptions in correcting different types of errors were shown to differ significantly.

Clasiyao, (2015), De Mello Paiva, (2011), Kivelä, (2008), and Renko, (2012) reported that learners and teachers showed positive attitude toward correcting grammatical errors. Many scholars have emphasized the importance of learners' errors. For example, according to Corder (1967, p.161),

they are significant in three different ways. First, to the teacher, in that they show how far towards the goal the learner has progressed. Second, they provide to the researcher evidence of how a language is acquired, what strategies the learner is employing in his learning of a language. Thirdly, they are indisputable to the learner himself because we can regard the making of errors as a device the learner uses in order to learn.

The next research question dealt with the differences and similarities between teachers' practices and learners' perceptions of different feedback types. As noted earlier, the purpose of comparing the learners' perceptions with the teachers' practices is to see to what extent they are con- 
gruent. Exploring teachers' practices with the learners' perceptions has indicated that the learners' stated beliefs do not always match the teachers' practices in the classroom. Learners showed strong disagreement toward neglecting errors. In other words they preferred the teachers to correct their grammatical errors during conversation. However, as it was evident from the observation, teachers usually neglected the learners' grammatical errors during conversation. To put it differently, there was a significant difference between teachers' practice and learners' perceptions. The other feedback types that were investigated include explicit correction and elicitation. Based on the findings, teachers seldom used these CF types in their classroom instruction. On the other hand, when the learners were asked about this feedback type for grammatical error correction during conversation, they showed strong agreement. In other words, they favored correcting their grammatical errors using explicit feedback or elicitation during conversation. Consequently, there are significant differences between the teachers' practices and learners' perceptions in choosing explicit correction or elicitation for correcting the learners' grammatical errors. In other words, recast was the only feedback that the teachers used less frequently in the class and learners disagreed with this kind of feedback at intermediate level.

The other important feedback type which illustrated the intermediate learners' agreement was metalinguistic feedback. Nevertheless, the results of classroom observation differed from the learners' perceptions. In other words, teachers hardly ever used metalinguistic feedback for correcting the learners' grammatical errors during the conversation. As a result of these findings, significant differences have been observed between teachers' practices and learners' perceptions.

Findings of many other studies are not congruent with the findings of the present study. Kivelä (2008), for example, reported that the most typical error correction strategies that were used by teachers were recast and negotiation while the least frequently used feedback as reported in the present study was recast. In another study, Khorshidi and Rassaei (2013) reported that explicit feedback was the least frequent feedback by the learners. But as suggested in this study, explicit feedback was the most favored feedback chosen by the learners. In a similar vein, Mendez and Cruz (2012) conducted a research about the learners' perceptions and practices related to oral CF in EFL classrooms. The obtained results indicated that unfocused oral $\mathrm{CF}$ is more favored by this group of teachers' practices.

\section{CONCLUSION}

This study sought to cast light on the relationship between the teachers' practices with the perceptions associated with the both learners' and teachers' perceptions to check beliefs against the teachers' actual practices. The other prominent purpose of this study was to detect the learners' ideas, as distinguished from the teachers' ideas or otherwise as distinguished from the teachers' practice in the classroom. A few similarities and differences in this regard were observed in this study. For example, recast was the only feedback that teachers did not use at the class and learners disagreed with this kind of feedback for correcting the intermediate learn- ers' grammatical errors. The other important finding was that explicit correction, elicitation, and repetition were the most highly effective feedback types from the learners' point of views. On the contrary, these three feedback types were hardly observed in the class. However, there is a possible risk that explicit correction, elicitation, and repetition may impede the conversation or slow down the communication, but, the learners showed strong agreement toward focused feedback types.

The other important finding involved the similarities between teachers' and learners' perceptions. Both teachers and learners preferred teacher correction to peer correction or self-correction. This correspondence may be because of the learners' dependence to teachers. Likewise, when the learners are corrected by their peers, they experience anxiety or feel embarrassed. Alternatively, the feeling of responsibility and management prompts correction (or feedback) on the teachers' part.

The other important finding concerned differences and similarities between teachers and learners in correcting different kinds of errors. Both teachers and learners preferred to correct the learners' frequent grammatical errors and serious errors for which there might be an awful lot of reasons. In fact, ignoring such errors would lead to the learners' inaccurate speech or fossilizations. Therefore, majority of teachers and learners have preferred to correct these two kinds of errors.

Pedagogically, the present study bears implications for classroom-based teaching and learning. As far as the former is concerned, a closer understanding can be achieved of teachers' preferred type of feedback. Within the context of the present study (i.e. Iran as a Middle Eastern country), traditional perspectives and norms within and about education lay a lot of emphasis on the teacher's role as the authority and source of knowledge in the classroom. This could, in turn, mean a more diversified role for the teacher who must play an active role in treating the learners' erroneous forms. On the other hand, in such contexts, a big methodological gap is noticed about an underestimated role of learner involvement in feedback which can be the subject of further investigations. Implications for learning may involve a great deal of support for the learners since they expect their teachers (again as a source of authority) to provide them with the correct forms and structures. This may give them a higher feeling of security compared to the time when they are exposed to feedback from their peers. Last of all, this study could imply that both learners and teachers believe in a hierarchy of error types that need to be treated differently. Further studies can address the nature of such a hierarchical categorization and which category of errors requires which type of feedback in the learners' and teachers' eyes.

\section{REFERENCES}

Al-Fake, A. M., \& Siddiek, A. G. (2013). Techniques used by teachers in correcting students' oral errors in an Omani boy's school. Theory and Practice in Language Studies, 3, 1770-1783.

Amador, Y. A. (2008). Learner attitude toward error correction in a beginners' English class. Revista Comunicación, 17(1), 18-28. 
Asmara, T. (2015). Learners' perceptions of teacher written feedback commentary in an ESL writing classroom. International Journal of English Language Teaching, 3, 38-53.

Braidi, S.M. (2002). Reexamining the role of recasts in native-speaker/nonnative-speaker interaction. Language Learning, 52, 1-42.

Burns, A. (1992). Teacher beliefs and their influence on classroom practice. Prospect, 3, 57-66.

Calsiyao, I. (2015). Corrective Feedback in Classroom Oral Errors among Kalinga Apayao State College Students. International Journal of Social Science and Humanities Research, 3, 394-400.

Carrol, S. (2001). Input and Evidence: The Raw Material of Second Language Acquisition. Amsterdam: John Benjamins.

Corder, S.P. (1976). The significance of learners' errors. IRAL, 5, 161-170.

De Mello Paiva, K. (2011). Brazilian English as foreign language teachers' beliefs about grammar-based feedback on L2 writing (Master's thesis, Iowa State University, Ames, Iowa). Retrieved from http://lib.dr.iastate.edu/ cgi/viewcontent.

Ellis, R. (2009). Corrective Feedback and Teacher Development. L2 Journal., 1, 3-18.

Ellis, R. (2006). Researching the effects of form-focused instruction on L2 acquisition. AILA Review, 19, 18-41.

Ellis, R. (2003). Task-based language learning and teaching. Oxford: Oxford University Press.

Ellis, R. (1994). The study of second language acquisition. Oxford: Oxford University Press.

Ellis, R., Basturkmen, H., \& Loewen, S. (2002). Doing focus-on-form. System, 30,419-432.

Ellis, R., Basturkmen, H., \& Loewen, S. (2001). Learner uptake in communicative ESL lessons. Language Learning, 51(2), 281-318.

Ellis, R., Loewen, S. \& Erlam, R. (2006). Implicit and explicit corrective feedback and the acquisition of L2 grammar. Studies in Second Language Acquisition, 28, 339-68.

Housen, A., \& Pierrard, M. (Eds.) (2005). Investigations in instructed second language acquisition. Mouton de Gruyter: Berlin.

Khatib, M. \& Derakhshan, A. (2011). A complementary-compensatory approach to teaching focus on form $/ \mathrm{S}$ in EFL/ESL classrooms. Theory and Practice in Language Studies, 1(7), 865-874.

Khorshidi, E., \& Rassaei, E. (2013). The effects of learners' gender on their preferences for corrective feedback. Journal of Studies in Learning and Teaching English, 1, 71-83.

Kivelä, S. (2008). Pupils'oral errors and teachers' practices on error correction: A classroom study. University of Tampere, School of Language, Translation and Literary Studies [online], Retrieved August, 2018 from http:// urn.fi/urn: nbn:fi: uta-1-17859.

Krashen, S. D. (1982). Principles and practice in second language acquisition. Oxford: Pergamon.
Liao, M., \& Wang, H. (2009). Perception differences of EFL teachers and students in grammar instruction and error correction. English Teaching and Learning, 1, 101-146.

Loewen, S. (2004). Uptake in incidental focus on form in meaning-focused ESL lessons. Language Learning, 54, 153-188.

Loewen, S. \& Nabei, T. (2007). Measuring the effects of oral corrective feedback on L2knowledge. In A. Mackey (Eds.), Conversational interaction in second language acquisition: A collection of empirical studies (pp.361-376). Oxford: Oxford University Press.

Long, M. H. (1996). The role of the linguistic environment in second language acquisition. In W. C. Ritchie \& T. K. Bhatia (Eds.), Handbook of second language acquisition (pp. 413-468). New York: Academic Press.

Lyster, R., \& Mori, H. (2006). Interactional feedback and instructional counterbalance. Studies in Second Language Acquisition, 28, 269-300.

Lyster, R., \& Ranta, L. (1997). Corrective feedback and learner uptake: Negotiation of form in communicative classrooms. Studies in Second Language Acquisition, 20, 37-66.

Mackey, A., Gass, S., \& McDonough, K. (2000). How do learners perceive interactional feedback? Studies in Second Language Acquisition, 22, 471-497.

Mendez, E., and Cruz, M. (2012). Teachers' perceptions about oral corrective feedback and their practice in EFL classrooms. PROFILE, 14(2), 63-75. Bogota, Colombia.

Park, G. (2010). Preference of corrective feedback Approaches perceived by native English teachers and Students. The Journal of Asia TEFL, 7, 29-52.

Renko, K. (2012). Finish EFL learners' perceptions on errors, corrective feedback and foreign language anxiety (Master's thesis), University of Jyväskylä. Retrieved 21 August, 2018 from https://jyx.jyu.fi/dspace/bitstream/handle/123456789.

Rassaei, E. \& Moinzadeh, A. (2011). Investigating the effects of three types of corrective feedback on the acquisition of English Wh-question forms by Iranian EFL learners. English Language Teaching, 4(2), 97-106.

Sheen, Y. (2011). Corrective feedback, individual differences and second language learning. Berlin, Germany:Springer.

Sheen, Y., \& Ellis, R. (2011). Corrective feedback in language teaching. In E. Hinkel (Ed.), Handbook of

research in second language teaching and learning (pp. 593610). New York: Routledge.

Sung, K., \& Tsai, H. (2014). Exploring student errors, teachers' corrective feedback, learner uptake and repair, and learners' preferences of corrective feedback. The Journal of Language Teaching and Learning, 4(1), 37-54.

Suwangard, N. (2014). Grammatical error correction and retention in EFL students in Thailand. IOSR Journal of Humanities and Social Science, 19, 51-58. 


\section{APPENDIX}

1. Gender:

2. Age:

Dear Teachers and Learners

We are collecting some information on learners' and teachers' beliefs about different aspects of corrective feedback. Please reflect your personal feeling regarding corrective feedback. Read each statement carefully and respond to what extent you agree or disagree with each statement. Please reflect on your personal feelings regarding language leaning. Read carefully each statement and indicate to what extent you agree or disagree by circling the statement that best describes how you feel. We will appreciate you if you could respond each statement with your personal idea. There are no risks or benefits to you. So, do not put your name on this questionnaire.

A: When do you want the learners' spoken grammatical errors to be treated?

1: As soon as grammatical errors are made even if it interrupts my speaking.
Very Effective
Effective
Neutral
Ineffective
Very Ineffective

2: After I finish speaking.

Very Effective $\quad$ Effective $\quad$ Neutral $\quad$ Ineffective $\quad$ VeryIneffective

3: After the activities.

Very Effective Effective Neutral Ineffective Very Ineffective

4: At the conclusion of class.

Very Effective $\quad$ Effective Neutral Ineffective $\quad$ Very Ineffective

B: How do you rate each type of spoken grammatical correction below?

1: I go? Repetition: the teacher emphasizes the students' grammatical errors by changing his/her tone of voice.
Very Effective
Effective
Neutral
Ineffective
Very Ineffective

2: "Go" is the present tense. You need to use the past tense "Went". (Explicit feedback: the teacher gives the correct form to the learner with a grammatical explanation.)
Very Effective
Effective
Neutral
Ineffective
Very Ineffective

3: Yesterday, I ................ (Elicitation: The teacher asks the learner to correct and complete the sentence.)
Very Effective
Effective
Neutral
Ineffective
Very Ineffective

4: really? What did you do there? (No corrective feedback: The teacher does not give corrective feedback on the learners' grammatical errors during conversation.)
Very Effective
Effective
Neutral
Ineffective
Very Ineffective

5: How does the verb change when we talk about the past? (Metalinguistic feedback: The teacher gives a hint or clue without specifically pointing out the grammatical errors during conversation.
Very Effective
Effective
Neutral
Ineffective
Very Ineffective

6: I went to the park. (Recast: the teacher repeats the learners' utterance in the correct form without pointing out the learners' grammatical error.)
Very Effective
Effective
Neutral
Ineffective
Very Ineffective]

C: How often do you want each of the following types of errors to receive corrective feedback?

1: serious spoken grammatical errors that may cause problems in a listeners' understanding.
Always(100\%)
Usually(80\%)
Sometimes (50\%)
Occasionally $(20 \%)$
Never $(0 \%)$ 
2: Less serious spoken grammatical errors that do not affect a listeners' understanding.
Always(100\%)
$\operatorname{Usually}(80 \%)$
Sometimes $(50 \%)$
Occasionally $(20 \%) \quad \operatorname{Never}(0 \%)$

3: Frequent spoken errors.
Always(100\%)
Usually $(80 \%)$
Sometimes $(50 \%)$
Occasionally $(20 \%)$
Never $(0 \%)$

4: Individual errors(errors that other learners may not make.)
Always(100\%)
Usually $(80 \%)$
Sometimes $(50 \%)$
Occasionally $(20 \%)$
Never $(0 \%)$

D: The following person should correct learners' grammatical errors.

1: Teachers
Strongly Agree
Agree
Neutral
Disagree
Strongly Disagree

2: Classmates
Strongly Agree
Agree
Neutral
Disagree
Strongly Disagree

3: The learner himself or herself

Strongly Agree Agree

Neutral

Disagree

Strongly Disagree 